\title{
Fluid shear stress enhances the cell volume decrease of osteoblast cells by increasing the expression of the $\mathrm{ClC}-3$ chloride channel
}

\author{
$\mathrm{LI} \mathrm{LIU}^{1 *}$, SIYI CAI ${ }^{2 *}$, GUIXING QIU ${ }^{2}$ and JIN LIN ${ }^{2}$ \\ ${ }^{1}$ Department of Medical Oncology, Affiliated Tumor Hospital of Xinjiang Medical University, Urumqi, Xinjiang 830011; \\ ${ }^{2}$ Department of Orthopedics, Peking Union Medical College Hospital, Beijing 100730, P.R. China
}

Received July 9, 2015; Accepted September 8, 2015

DOI: $10.3892 /$ br.2016.595

\begin{abstract}
ClC-3 is a volume-sensitive chloride channel that is responsible for cell volume adjustment and regulatory cell volume decrease (RVD). In order to evaluate the effects of fluid shear stress (FSS) stimulation on the osteoblast ClC-3 chloride channel, MC3T3-E1 cells were stimulated by FSS in the experimental group. Fluorescence quantitative polymerase chain reaction was used to detect changes in ClC-3 mRNA expression, the chloride ion fluorescent probe $N$-(ethoxycarbonylmethyl)-6-methoxyquinolinium bromide (MQAE) was used to detect the chloride channel activity, and whole-cell patch clamping was used to monitor the changes in the volume-sensitive chloride current activated by a hypotonic environment following mechanical stimulation. The results show that the expression of the osteoblast chloride channel ClC-3 was significantly higher in the FSS group compared with the control group. MQAE fluorescence intensity was significantly reduced in the FSS group compared to the control group, suggesting that mechanical stimulation increased chloride channel activity and increased the efflux of intracellular chloride ions. Image analysis of osteoblast volume changes showed that osteoblast RVD was enhanced by mechanical stimulation. Whole-cell patch clamping showed that the osteoblast volume-sensitive chloride current was larger in the stimulated group compared to the control group, suggesting that elevated $\mathrm{ClC}-3$ chloride channel expression results in an increased volume-sensitive chloride current. In conclusion, FSS stimulation enhances the RVD of osteoblast cell by increasing the expression of the $\mathrm{ClC}-3$ and enhancing the chloride channel activity.
\end{abstract}

Correspondence to: Professor Jin Lin, Department of Orthopedics, Peking Union Medical College Hospital, 1 Shuaifuyuan, Beijing 100730, P.R. China

E-mail: drlinjin@sina.com

*Contributed equally

Key words: fluid shear stress, ClC-3, volume sensitivity, osteoblast

\section{Introduction}

Bone is a dynamic structure that is undergoing constant change and remodeling in response to the changing environment. Under conditions such as long bed rest, lack of exercise or microgravity, there is a long-term reduction in the external force acting on the bone, resulting in a significant reduction of bone mass (1). Conversely, an increase in external forces acting upon the bone can increase the net accumulation of bone (2). Various in vitro loading techniques, such as cell swelling, substrate stretch loading and fluid shear stress (FSS), are used in the study of osteocyte response to mechanical stimulation. However, the majority of studies do not recapitulate osteoblast anabolism under mechanical stimulation, including the activation of intracellular chloride ions, chloride channel genes and channel proteins (3-7). In fact, studies have shown that numerous ion channels [such as $\mathrm{Ca}^{2+}$ channels (8) and $\mathrm{K}^{+}$channels (9)] have a role in osteogenic differentiation. $\mathrm{ClC}-3$ is a subtype of the volume-sensitive chloride channel family that has a role in cell volume regulation (10-12), as well as in cell proliferation (13), apoptosis (10), cell cycle progression (14) and intracellular acidification regulation in the osteoclast (15). Studies have also reported the involvement of chloride channels in the metabolism of osteoblasts, for example, $\mathrm{ClC}-3$ protein expression can promote osteogenesis via Runx 2 gene expression in mouse osteoblasts (16). However, the physiological mechanism of CLC-3 in the dynamic structure of osteoblast remains to be elucidated. In the present study, the role of $\mathrm{ClC}-3$ was investigated in osteoblast response to mechanical stress and report FSS regulatory cell volume decrease (RVD) via ClC-3.

\section{Materials and methods}

Cell lines. Mouse embryonic osteogenic precursor cells (MC3T3-E1) were obtained from the Institute of Basic Medical Sciences, Chinese Academy of Medical Sciences (Beijing, China).

Extracellular perfusate and glass microelectrode internal fluid. The isosmotic perfusate had an osmotic pressure of $300 \mathrm{mOsmol} / \mathrm{l}$ and was composed mainly of the following: $70 \mathrm{mmol} / 1 \mathrm{NaCl}, 0.5 \mathrm{mmol} / 1 \mathrm{MgCl}_{2}, 2 \mathrm{mmol} / 1 \mathrm{CaCl}_{2}$, $10 \mathrm{mmol} / 1 \mathrm{HEPES}$ and $140 \mathrm{mmol} / \mathrm{l} \mathrm{D}$-mannitol. The 
extracellular perfusate was adjusted to $\mathrm{pH} 7.4$ using a Tris-base solution. The hypotonic solution (Hypo) had an osmotic pressure of $160 \mathrm{mOsmol} / \mathrm{l}$ and had the same composition as the isosmotic perfusate, except for the omission of D-mannitol. The electrode internal liquid contained $70 \mathrm{mmol} / \mathrm{l} \mathrm{NMDG}-\mathrm{Cl}$, $1.2 \mathrm{mmol} / 1 \mathrm{MgCl}_{2}, 10 \mathrm{mmol} / 1 \mathrm{HEPES}, 1 \mathrm{mmol} / 1 \mathrm{EGTA}$, $140 \mathrm{mmol} / \mathrm{l} \mathrm{D}$-mannitol and $2 \mathrm{mmol} / \mathrm{l}$ ATP. Hydrochloric acid was used to adjust to $\mathrm{pH}$ 7.25. A freezing point osmometer (Advanced $^{\mathrm{TM}}$ 3250; Advanced Instruments, Inc., Norwood, MA, USA) was used to detect osmotic pressure following liquid preparation.

Cell culture. MC3T3-E1 cells were cultured in DMEM (Gibco, Grand Island, NY, USA) containing $10 \%$ fetal bovine serum (Gibco) in an incubator maintained at $5 \% \mathrm{CO}_{2}, 37^{\circ} \mathrm{C}$ and saturated humidity. Routine cell passaging was performed to maintain the cell line. Cells were digested prior to the experiment, and the cell suspension was seeded in a plastic plate with a diameter of $35 \mathrm{~mm}$. The cells attached as a monolayer and were placed in the incubator. After $10 \mathrm{~min}$ of cell adherence, patch clamping was performed. The experimental group was stimulated with FSS using the FSS device. The cells were stimulated once every $24 \mathrm{~h}$ for a total of $48 \mathrm{~h}$, and each stimulus comprised a loading time of $30 \mathrm{~min}$. Cells in the control group were not administered mechanical stimulation, however, they were also cultured in the square groove in the middle of the flow chamber system. Aside from the lack of FSS stimulation, the control group had the same physical environment as the experimental group.

FSS loading. MC3T3-E1 cells were seeded on rectangular cover glass slips $(50 \times 20 \times 0.20 \mathrm{~mm})$ at a density of $2 \times 10^{4}$ cells $/ \mathrm{cm}^{2}$, and the coverslips were placed in culture plates with $5 \mathrm{ml}$ of complete medium. Cells were cultured overnight to allow for cell adherence and fusion. In the experimental group, the cover glass was subsequently placed in a square groove in the middle of the flow chamber system (which was previously sterilized by ultraviolet irradiation for $1 \mathrm{~h}$ ), thus forming a closed loop with the other components of the perfusion system. Circulation of the perfusate was promoted by the power resulting from the negative pressure of the peristaltic pump. The association between FSS and the flow rate of the osteoblast and the flow chamber was $\tau=6 \mathrm{Q} \mu / \mathrm{bh}^{2}$, where $\tau$ was the FSS at the bottom of the chamber (namely, the forces acting upon the cells) (dyne/ $\left.\mathrm{cm}^{2}\right), \mathrm{Q}$ was the flow rate of circulation fluid $\left(\mathrm{cm}^{3} / \mathrm{sec}\right)$, $\mu$ was the viscosity of the circulation fluid $\left(0.01 \mathrm{dynes} / \mathrm{cm}^{2}\right)$, $\mathrm{b}$ was the width of the chamber $(2 \mathrm{~cm})$ and $\mathrm{h}$ was the height of the chamber $(0.025 \mathrm{~cm})$. A horizontal FSS magnitude that was in accordance with the most effective way to stimulate osteoblast differentiation was employed (8). The rotational speed of the peristaltic pump was adjusted to $28 \mathrm{rpm}$, and the flow rate in the flow chamber $(\mathrm{Q})$ was $49.7 \mathrm{ml} / \mathrm{min}\left(0.833 \mathrm{~cm}^{3} / \mathrm{sec}\right)$. The magnitude of the FSS $(\tau)$ at the bottom of the chamber was 1.2 $\mathrm{Pa}\left(1.2 \mathrm{~Pa}=12\right.$ dyne $\left./ \mathrm{cm}^{2}\right)$.

Effect of FSS simulation on mRNA expression of ClC-3 was quantified by quantitative polymerase chain reaction ( $q P C R$ ). Cells from the experimental and control groups were collected prior and subsequent to mechanical stimulation and washed two times with phosphate-buffered saline. TRIzol (Invitrogen
Life Technologies, Carlsbad, CA, USA) was added to the samples and the total RNA was extracted. Reverse transcription kits (DRR037S; Takara Bio, Dalian, China) were used for cDNA synthesis, and SYBR ${ }^{\circledR}$ Premix Ex Taq ${ }^{\mathrm{TM}}$ (Takara Bio) was used to detect the mRNA expression levels of ClC-3. The total volume of the cDNA (10-30 ng) reaction system was $20 \mu 1$. The thermal cycling reaction conditions were as follows: $95^{\circ} \mathrm{C}$ for $30 \mathrm{sec}$; followed by $95^{\circ} \mathrm{C}$ for $5 \mathrm{sec}$ and $60^{\circ} \mathrm{C}$ for $34 \mathrm{sec}$, for a total of 45 cycles. Fluorescence quantitative analysis was used for relative quantitation. The $2^{-\Delta \Delta C t}$ formula was used for data analysis.

Cell volume measurement. MC3T3-E1 cells in the logarithmic growth phase were digested by conventional methods and prepared as a cell suspension. Cells from the experimental and control groups were separately seeded in the perfusion groove of a custom-made culture plate, and after $20 \mathrm{~min}$ of cell adhesion, the experiment was conducted. An inverted phase contrast microscope (DMI6000 B; Leica, Mannheim, Germany) was used in fixed view mode to continuously acquire cell images. Image-Pro Plus (Media Cybernetics, Rockville, MD, USA) was used to control image acquisition. The perfusion speed was set at $4 \mathrm{ml} / \mathrm{min}$. Cells were soaked in isotonic solution for $5 \mathrm{~min}$, and the baseline cell volume was observed. The cells were subsequently perfused with Hypo for $20 \mathrm{~min}$ and subsequently re-perfused with isotonic solution for $5 \mathrm{~min}$. Subsequent to the experiment, Image-Pro Plus was used to analyze and measure cell volume. Standardized cell volume (Vst) was calculated according to the formula $\mathrm{Vst}=(\mathrm{Vt} / \mathrm{Vo}) \times 100$, where $\mathrm{Vt}$ was the cell volume measured in real time and Vo was the average volume of the same cell under isotonic conditions. All the experiments were performed at room temperature $\left(20-24^{\circ} \mathrm{C}\right)$.

Determination of intracellular chloride ion concentration. A chloride ion fluorescence probe was used to detect and analyze the chloride channel activity of MC3T3-E1 cells prior and subsequent to mechanical stimulation. The chloride ion fluorescent probe $N$-(ethoxycarbonylmethyl)-6-methoxyquinolinium bromide (MQAE) (Beyotime Institute of Biotechnology, Shanghai, China) was excited at a wavelength of $355 \mathrm{~nm}$, and emitted light was collected at a wavelength of $460 \mathrm{~nm}$. The fluorescence intensity of the probe was inversely proportional to the chloride ion concentration. MC3T3-E1 cells were digested with trypsin prior and subsequent to mechanical stimulation and were subsequently seeded in a culture plate specifically designed for confocal microscopy. After $12 \mathrm{~h}$ of cell adhesion, the medium was replaced with culture medium containing $5 \mathrm{mmol} / \mathrm{l} \mathrm{MQAE}$, and the cells were cultured in a $37^{\circ} \mathrm{C}$ incubator for $1 \mathrm{~h}$. The cells were washed, and the intracellular MQAE fluorescence was observed with a fluorescence microscope.

Whole-cell patch clamp recording. Borosilicate glass capillary tubes (outside diameter, $1.5 \mathrm{~mm}$; inside diameter, $0.86 \mathrm{~mm}$ ) were used for multiple-step drawing in an electrode puller (P-2000; Sutter Instruments, Novato, CA, USA). The electrode was filled with electrode fluid, and the resistance at the electrode tip was 5-10 M $\Omega$. The whole-cell membrane current of a single cell was amplified through an EPC-9 amplifier (HEKA Elektronik Dr. Schulze GmbH, Lambrecht, Germany), and via 
filtering by $2.9 \mathrm{kHz}$, the currents were recorded to the Pulse and Pulsefit software system (HEKA Elektronik Dr. Schulze $\mathrm{GmbH}$ ). Whole-cell patch clamp recording parameters were as follows $(11,17)$ : Under the voltage clamp mode, the cells were clamped at $0, \pm 40$ and $\pm 80 \mathrm{mV}$. Each clamp pulse was held for $200 \mathrm{msec}$ with an interval gap of $4 \mathrm{sec}$. The experiment was performed at room temperature $\left(20-24^{\circ} \mathrm{C}\right)$. Following recording the whole-cell current, a stable background current was recorded. Hypo solution was perfused over the cells to induce a volume-sensitive chloride current. When the current reached a stable peak value, a chloride-channel blocker was added, and the recording was ended when the current reached a stable minimum value.

Statistical analysis. SPSS 13.0 (SPSS, Inc., Chicago, IL, USA) was used for variance analysis on all the data with a significance level of $\alpha=0.05$, and $\mathrm{P}<0.05$ was considered to indicate a statistically significant difference. The data are presented as mean \pm standard deviation.

\section{Results}

FSS simulation increases $m R N A$ expression of $\mathrm{ClC}-3$. An FSS device was used to stimulate MC3T3-E1 osteoblasts by FSS once every $24 \mathrm{~h}$ for a total of $48 \mathrm{~h}$, with each stimulation having a duration of $30 \mathrm{~min}$. A control group of osteoblasts was cultured in the same physical environment, without FSS stimulation. After $48 \mathrm{~h}$, the mRNA expression of ClC-3 was quantified. The results showed a significantly higher mRNA expression in the experimental group compared to the control group, suggesting that osteoblasts are sensitive to FSS and can increase the gene expression of ClC-3 ( $n=3 ; \mathrm{P}<0.01$; Fig. 1).

FSS stimulation enhances RVD in MC3T3-E1 osteoblasts. Cell volumes of the control and experimental groups were maximally swollen $\sim 5 \mathrm{~min}$ after hypotonic stimulation and the standardized cell volumes were $148.00 \pm 1.05$ and $146.63 \pm 2.45 \%$, respectively; chloride channels are subsequently activated by cell volume swelling, allowing chloride ions to flow out of the cell and to drive the efflux of water, and the RVD is activated (Fig. 2A). Following stimulation, the RVD of the control and experimental groups were $33.33 \pm 4.45$ and $51.94 \pm 6.35 \%$, respectively $(\mathrm{n}=3 ; \mathrm{P}<0.05)$ (Fig. $2 \mathrm{~B})$. Combined with the qPCR data, these results suggest that the expression of osteoblast chloride channels is increased by mechanical stimulation. The increase in chloride channel expression results in increased chloride ion efflux and enhanced osteoblast RVD.

FSS stimulation induces chloride ion efflux in MC3T3-E1 osteoblasts. MQAE is a widely used chloride ion fluorescent probe. MQAE fluorescence intensity decreases proportionally with the increase of chloride ion concentration. MQAE was used to detect and analyze the chloride channel activity of MC3T3-E1 cells prior and subsequent to mechanical stimulation. The excitation wavelength of MQAE was $355 \mathrm{~nm}$, and the emission wavelength was $460 \mathrm{~nm}$ (green). After $48 \mathrm{~h}$ of FSS stimulation, the MQAE fluorescence intensity of the control group was stronger compared to the experimental groups (Fig. 3), which implied that the chloride channel activity of experimental groups was increased.

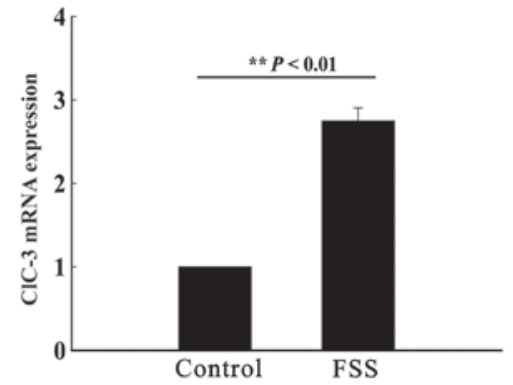

Figure 1. Quantitative polymerase chain reaction analysis of the effect of fluid shear stress (FSS) on ClC-3 mRNA expression in MC3T3-E1 cells. The mRNA expression of $\mathrm{ClC}-3$ was significantly higher in the experimental group (FSS) compared to the control groups $\left(\mathrm{n}=3,{ }^{* *} \mathrm{P}<0.01\right)$.

$\mathbf{A}$

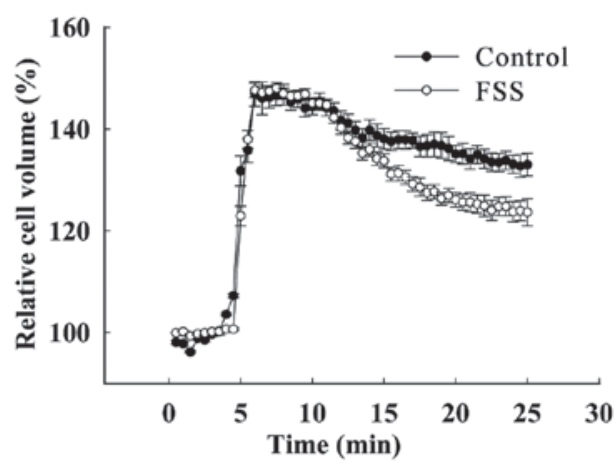

B

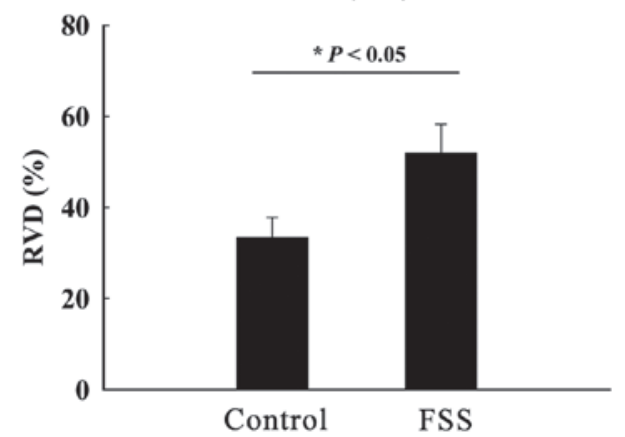

Figure 2. Effect of fluid shear stress (FSS) on regulatory volume decrease (RVD) in MC3T3-E1 cells. (A) Relative cell volumes of the control and FSS groups. The volumes reach a peak $\sim 5 \mathrm{~min}$ after hypotonic stimulation and subsequently decreased. (B) The RVD of the control and experimental groups were $33.33 \pm 4.45$ and $51.94 \pm 6.35 \%$, respectively $\left(n=3,{ }^{*} \mathrm{P}<0.05\right)$.

FSS stimulation increases the current density of the volume-activated chloride current in MC3T3-El osteoblasts. Whole-cell patch clamping was used to monitor changes in the volume-sensitive chloride current activated by a hypotonic environment prior and subsequent to FSS stimulation. The background current was low and stable in cells perfused with isotonic solution, and the current was activated by hypotonic solution (Fig. 4A). Under isotonic solution, clamped at a voltage of +80 and $-80 \mathrm{mV}$, the currents of the control group were $5.56 \pm 1.39$ and $-3.67 \pm 2.25 \mathrm{pA} / \mathrm{pF}$, respectively, and the experimental group were $6.33 \pm 1.65$ and $-3.85 \pm 2.73 \mathrm{pA} / \mathrm{pF}$, respectively ( $\mathrm{n}=6 ; \mathrm{P}>0.05$ ) (Fig. 4B). When the perfusion fluid was changed to hypotonic solution, the cells swelled and the current increased, potentially activating the volume-sensitive chloride current increased significantly. Under clamping at $+80 \mathrm{mV}$, the current density of the control group was 


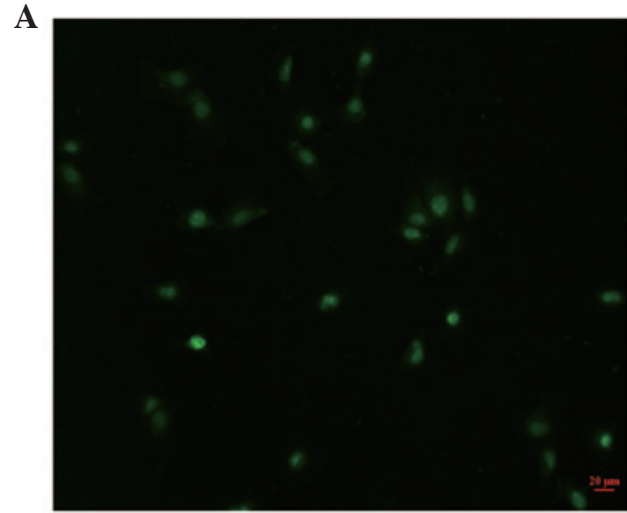

Control

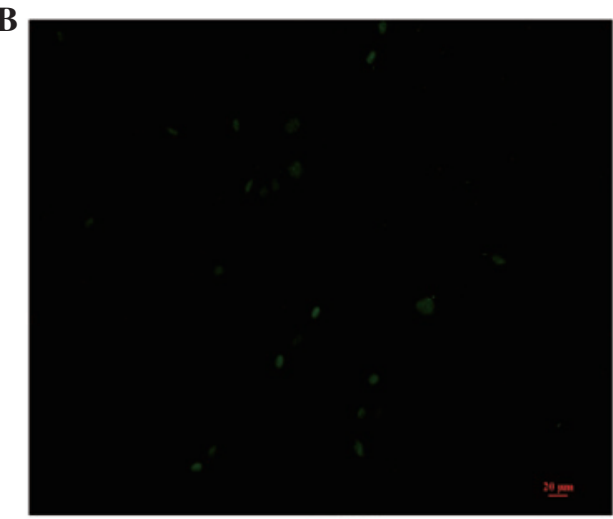

FSS

Figure 3. Effect of fluid shear stress (FSS) stimulation on intracellular Cl-concentration in MC3T3-E1 cells. After 48 h of FSS stimulation, the $\mathrm{N}$-(ethoxycarbonylmethyl)-6-methoxyquinolinium bromide fluorescence intensity of the (A) control group was stronger compared to the (B) experimental groups.

A

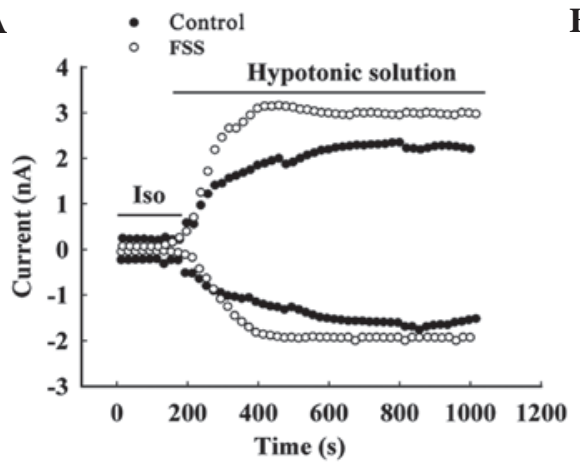

B
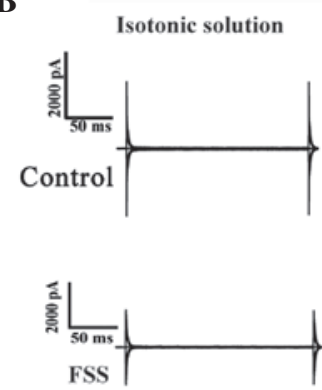

C

Hypotonic solution
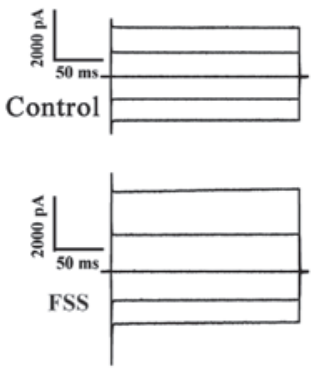

Figure 4. Effect of fluid shear stress (FSS) stimulation on whole-cell chloride current induced by hypotonic conditions in MC3T3-E1 cells. (A) The background current was low and stable in isotonic solution, and the current was activated by hypotonic solution. (B) The currents of the control and FSS groups at a voltage of +80 and $-80 \mathrm{mV}$ under isotonic solution. (C) The currents of the control and FSS groups at a voltage of +80 and $-80 \mathrm{mV}$ under hypotonic solution.

$58.16 \pm 3.20 \mathrm{pA} / \mathrm{pF}$, and for the experimental group was 81.34 $\pm 5.87 \mathrm{pA} / \mathrm{pF},(\mathrm{n}=6 ; \mathrm{P}<0.01)$. Under clamping at $-80 \mathrm{mV}$, the current density was $-39.41 \pm 4.86 \mathrm{pA} / \mathrm{pF}$ in the control group and $-42.29 \pm 4.51 \mathrm{pA} / \mathrm{pF}$ in the experimental group $(\mathrm{n}=6$; $\mathrm{P}<0.05$ ) (Fig. 4C).

\section{Discussion}

Bone metabolism has a strong regulatory system for mechanical homeostasis, which adapts to the changed biomechanical circumstances by constant self-regulation (18). Bone remodeling partly contributes to the mechanical environment, such as body weight, loading, muscle tension and physical activity. In bone tissue, sensors such as osteoblasts, bone cells and bone lining cells can convert a mechanical stimulation signal into biochemical signals. Bone can be generated and reconstructed under mechanical stimulation. Cells under static stretching do not engage in active bone remodeling; only dynamic mechanical loading can cause significant anabolic effects in vivo. The effects of tension on bone tissue are affected by numerous factors, such as the magnitude, duration and rate of the applied force. Generally, smaller and longer loading forces result in similar protein synthesis as larger and shorter forces (2). The majority of investigators have hypothesized that the regulation of cell volume relies on the participation of the chloride channel superfamily, including the ClC-3. Mutations in these channels produce several genetic diseases, including cardiovascular disease (19), hypertension (20), stroke (21) and osteosarcoma (22). ClC-7 has been reported as a late endosomal to lysosomal chloride channel that has a key role in acidifying the extracellular lysosome between osteoclasts and the bone (23). The physiological role of CLC-3 in the dynamic structure of bone remains to be elucidated.

In the present study, FSS stimulation was used to imitate the physiological stimulation of the skeleton and to evaluate the changes in the volume-sensitive chloride channel. After $48 \mathrm{~h}$ of intermittent FSS stimulation, the ClC-3 mRNA expression of FSS group was significantly higher compared to the control group, suggesting that osteoblasts are sensitive to external FSS and can increase the gene expression of $\mathrm{ClC}-3$. Cell volume regulation is one of the basic physiological functions of cells. In the hypotonic solution, cells initially swell, subsequently decrease their volume through RVD, and finally return to their baseline volume. Chloride ion efflux is a key component of the RVD process, with $\mathrm{ClC}-3$ considered a candidate volume-sensitive chloride channel. The RVD capacity of FSS stimulated osteoblasts was higher compared to that of the control group. Furthermore, the chloride ion fluorescence probe MQAE was used to detect the intracellular chloride ion concentration in osteoblasts following FSS stimulation. Green fluorescence was significantly decreased following stimulation, indicating that the chloride channel 
activity was enhanced. These data, combined with the aforementioned results, lead us to hypothesize that mechanical stimulation increases the expression of osteoblast chloride channels. When chloride channel expression is increased, chloride ion efflux is increased due to hypotonic stimulation. The chloride ion fluorescent probe in the present experiments showed that intracellular chloride ion concentration was higher in the control group compared to the FSS group. These experiments show that FSS stimulation increases chloride channel expression, strengthens the activity of chloride channels, increases chloride ion efflux, decreases intracellular chloride ion concentration and increases osteoblast RVD. Furthermore, whole-cell patch clamping was used to detect changes in the volume-sensitive chloride current activated by a hypotonic environment prior and subsequent to FSS. The results show that following FSS treatment, the current density of the volume-sensitive chloride current activated by a hypotonic environment was significantly higher in the stimulated group compared to the control group. These results suggest that FSS treatment increases the expression of the osteoblast $\mathrm{ClC}-3$ chloride channel and increases the chloride current.

In the present study, the mechanism of mechanical signal transduction was investigated in osteoblasts, focusing on ion channels as signal transducers. FSS stimulation enhanced the RVD of osteoblast cell by increasing the expression of the $\mathrm{ClC}-3$ and activating the chloride channel. The study also provides further insights into the roles of chloride channels in the procession of osteoclasts metabolism and homeostasis.

\section{References}

1. Bikle DD, Sakata T and Halloran BP: The impact of skeletal unloading on bone formation. Gravit Space Biol Bull 16: 45-54 2003.

2. Burr DB, Robling AG and Turner CH: Effects of biomechanical stress on bones in animals. Bone 30: 781-786, 2002.

3. Dutta AK, Woo K, Khimji AK, Kresge C and Feranchak AP: Mechanosensitive Cl-secretion in biliary epithelium mediated through TMEM16A. Am J Physiol Gastrointest Liver Physiol 304: G87-G98, 2013.

4. Heo J, Sachs F, Wang J and Hua SZ: Shear-induced volume decrease in MDCK cells. Cell Physiol Biochem 30: 395-406, 2012.

5. Qin KR, Xiang C and Cao LL: Dynamic modeling for flow-activated chloride-selective membrane current in vascular endothelial cells. Biomech Model Mechanobiol 10: 743-754, 2011.

6. Dyrda A, Cytlak U, Ciuraszkiewicz A, Lipinska A, Cueff A, Bouyer G, Egée S, Bennekou P, Lew VL and Thomas SL: Local membrane deformations activate $\mathrm{Ca}^{2+}$-dependent $\mathrm{K}^{+}$and anionic currents in intact human red blood cells. PLoS One 5: e9447, 2010.
7. Kefaloyianni E and Coetzee WA: Transcriptional remodeling of ion channel subunits by flow adaptation in human coronary artery endothelial cells. J Vasc Res 48: 357-367, 2011.

8. Genetos DC, Geist DJ, Liu D, Donahue HJ and Duncan RL: Fluid shear-induced ATP secretion mediates prostaglandin release in MC3T3-E1 osteoblasts. J Bone Miner Res 20: 41-49, 2005.

9. Cha SK, Kim JH and Huang CL: Flow-induced activation of TRPV5 and TRPV6 channels stimulates $\mathrm{Ca}(2+)$-activated $\mathrm{K}(+)$ channel causing membrane hyperpolarization. Biochim Biophys Acta 1833: 3046-3053, 2013.

10. Zhang H, Li H, Yang L, Deng Z, Luo H, Ye D, Bai Z, Zhu L, Ye W, Wang L, et al: The ClC-3 chloride channel associated with microtubules is a target of paclitaxel in its induced-apoptosis. Sci Rep 3: 2615, 2013.

11. Wang L, Chen L and Jacob TJC: The role of $\mathrm{ClC}-3$ in volume-activated chloride currents and volume regulation in bovine epithelial cells demonstrated by antisense inhibition. J Physiol 524: 63-75, 2000.

12. Duan D, Cowley S, Horowitz B and Hume JR: A serine residue in ClC-3 links phosphorylation-dephosphorylation to chloride channel regulation by cell volume. J Gen Physiol 113: 57-70, 1999.

13. Zhu L, Yang H, Zuo W, Yang L, Zhang H, Ye W, Mao J, Chen L and Wang L: Differential expression and roles of volume-activated chloride channels in control of growth of normal and cancerous nasopharyngeal epithelial cells. Biochem Pharmacol 83: 324-334, 2012.

14. Mao J, Li X, Chen W, Xu B, Zhang H, Li H, Wang L, Jin X, Zhu J, Lin G, et al: Cell cycle-dependent subcellular distribution of ClC-3 in HeLa cells. Histochem Cell Biol 137: 763-776, 2012.

15. Wang L, Ma W, Zhu L, Ye D, Li Y, Liu S, Li H, Zuo W, Li B, Ye W, et al: $\mathrm{ClC}-3$ is a candidate of the channel proteins mediating acid-activated chloride currents in nasopharyngeal carcinoma cells. Am J Physiol Cell Physiol 303: C14-C23, 2012.

16. Wang H, Mao Y, Zhang B, Wang T, Li F, Fu S, Xue Y, Yang T, Wen X, Ding Y, et al: Chloride channel ClC-3 promotion of osteogenic differentiation through Runx2. J Cell Biochem 111: 49-58, 2010.

17. Yang L, Ye D, Ye W, Jiao C, Zhu L, Mao J, Jacob TJ, Wang L and Chen L: ClC-3 is a main component of background chloride channels activated under isotonic conditions by autocrine ATP in nasopharyngeal carcinoma cells. J Cell Physiol 226: 2516-2526, 2011.

18. Robling AG and Turner $\mathrm{CH}$ : Mechanical signaling for bone modeling and remodeling. Crit Rev Eukaryot Gene Expr 19: 319-338, 2009

19. Duan DD: The ClC-3 chloride channels in cardiovascular disease. Acta Pharmacol Sin 32: 675-684, 2011.

20. Shi XL, Wang GL, Zhang Z, et al: Alteration of volume-regulated chloride movement in rat cerebrovascular smooth muscle cells during hypertension. Hypertension 49: 1371-1377, 2007.

21. Zhang YP, Zhang H and Duan DD: Chloride channels in stroke. Acta Pharmacol Sin 34: 17-23, 2013.

22. Cai S, Zhang T, Zhang D, Qiu G and Liu Y: Volume-sensitive chloride channels are involved in cisplatin treatment of osteosarcoma. Mol Med Rep 11: 2465-2470, 2015.

23. Kornak U, Kasper D, Bösl MR, Kaiser E, Schweizer M, Schulz A, Friedrich W, Delling G and Jentsch TJ: Loss of the ClC-7 chloride channel leads to osteopetrosis in mice and man. Cell 104: 205-215, 2001. 